\title{
Virtual Collaboration in the Online Educational Setting: A Concept Analysis
}

Henny Breen

Linfield College - Portland Campus Nursing \& Online and Continuing Education

Follow this and additional works at: https://digitalcommons.linfield.edu/nursfac_pubs

Part of the Health and Physical Education Commons, Nursing Commons, and the Online and Distance Education Commons

\section{DigitalCommons@Linfield Citation}

Breen, Henny, "Virtual Collaboration in the Online Educational Setting: A Concept Analysis" (2013). Faculty Publications. Accepted Version. Submission 2.

https://digitalcommons.linfield.edu/nursfac_pubs/2

This Accepted Version is protected by copyright and/or related rights. It is brought to you for free via open access, courtesy of DigitalCommons@Linfield, with permission from the rights-holder(s). Your use of this Accepted Version must comply with the Terms of Use for material posted in DigitalCommons@Linfield, or with other stated terms (such as a Creative Commons license) indicated in the record and/or on the work itself. For more information, or if you have questions about permitted uses, please contact digitalcommons@linfield.edu. 


\begin{abstract}
Purpose. This study was designed to explore the concept of virtual collaboration within the context of an online learning environment in an academic setting.

Method. Rodgers' method of evolutionary concept analysis was used to provide a contextual view of the concept to identify attributes, antecedents, and consequences of virtual collaboration. Findings. Commonly used terms to describe virtual collaboration are collaborative and cooperative learning, group work, group interaction, group learning and teamwork. A constructivist pedagogy, group-based process with a shared purpose, support and web-based technology are required for virtual collaboration to take place. Consequences of virtual collaboration are higher order thinking and learning to work with others.

Conclusion: A comprehensive definition of virtual collaboration is offered as an outcome of this analysis. Clarification of virtual collaboration prior to using it as a pedagogic tool in the online learning environment will enhance nursing education with the changes in nursing curriculum being implemented today. Further research is recommended to describe the developmental stages of the collaborative process among nursing students in online education and how virtual collaboration facilitates collaboration in practice.
\end{abstract}

Search Terms: collaboration, concept analysis, online education, distance education, virtual classrooms, nursing 
Virtual Collaboration in the Online Educational Setting: A Concept Analysis

Collaborative skills are essential to nursing education as reflected in the newly adopted document by the American Association of Colleges of Nursing (2008) that defines the essentials of baccalaureate education for professional nursing practice. A baccalaureate program is expected to prepare a graduate to "use inter- and intraprofessional communication and collaborative skills to deliver evidence based, patient centered care" (AACN, 2008, p. 22). There is a plethora of research in online education for a multitude of different professional disciplines in a number of different countries using the concept of collaboration. Terms such as collaborative learning, collaborative groups, and collaborative tools are frequently mentioned. The concept, however, is rarely defined. This demonstrates a lack of clarity as to what virtual collaboration really means. In order to conduct research using a concept like virtual collaboration, it must be well-defined (Tofthagen \& Fagerstrøm, 2010). It is necessary to clarify and refine the concept of collaboration within the educational setting prior to using it as a pedagogic tool (Vallance, Towndrow, \& Wiz, 2009) to better prepare nursing students for intraprofessional and interprofessional collaboration in practice.

This paper, using an evolutionary concept analysis of virtual collaboration in online education, is the beginning step towards research aimed at understanding how students learn to collaborate in the online educational environment.

\section{Background}

Two concept analyses found in the literature refer to interdisciplinary collaboration in the clinical setting. Henneman, Lee, and Cohen (1995), using Walker \& Avant's method of concept analysis, focused on the outcome of collaboration whereas Petri (2010) using Rodger's Evolutionary View of Concept Analysis focused on the process of interdisciplinary collaboration 
Henneman, Lee, and Cohen (1995) identified joint venture, cooperative endeavor, willing participation, team approach, non-hierarchical relationships, shared planning, decision making, responsibility and power as the defining attributes of collaboration. The model case reviewed a situation in which a physician and charge nurse shared information to come to a decision about making room in the intensive care unit for a new patient from the emergency room. All the defining attributes were present. No clear theoretical or operational definition was offered to clearly differentiate collaboration from cooperation, consultation, teamwork, or problem solving found in interdisciplinary teams.

Petri (2010) found three critical attributes that were consistently used in the nursing, medicine, and social work literature. The attributes were problem-focused process, sharing, and working together. Petri (2010) offered the following theoretical definition for practice; “.....an interpersonal process characterized by healthcare professionals from multiple disciplines with shared objectives, decision-making, responsibility, and power working together to solve patient care problems" $(\mathrm{p}, 80)$. The definition goes on to suggest that the process is best achieved "through an interprofessional education that promotes an atmosphere of mutual trust and respect, effective and open communication, and awareness and acceptance of the roles, skills, and responsibilities of the participating disciplines (Petri, 2010, p. 80). Therefore, there is a need for clarification of the concept that can be applied to the learning experience of nursing students.

\section{Concept Analysis with an Evolutionary View}

Rodgers' (2000) historically significant approach to concept analysis was used to provide a developmental and contextual view of virtual collaboration.. Concepts are dynamic and context dependent resulting in adaptations or changes over time or across situations. Rodgers evolutionary approach to concept analysis is inductive with a focus on its current use in order to 
uncover its attributes with an emphasis on context and time to bring the clarity needed for further study (Rodgers, 2000; Tofthagen \& Fagerstrøm, 2010). While the use of the term collaboration is extensive and recognized as critical to learning, operationalization of the concept within research and education has remained elusive (Gajda, 2009; Vallance et al., 2009). By contrast, more work has been done in defining the concept for nursing practice.

The evolutionary method of concept analysis developed by Rodgers (2000, p. 85) includes the following primary activities:

- identification of the concept of interest and associated expressions

- identification and selection of an appropriate realm (setting and sample) for data collection

- collection of the data to identify the attributes of the concept and the contextual basis of the concept including interdisciplinary, sociocultural, and temporal (antecedent and consequential occurrences) variations

- analysis of the data regarding the above characteristics of the concept

- identification of an exemplar if appropriate

- identification of implications, hypotheses, and implications for further development of the concept

Each of the above activities is used in this concept analysis.

\section{Method}

\section{Data Sources}

The literature search for this analysis was done using electronic databases. The search terms used included collaboration, cooperative learning, teamwork, virtual classrooms, electronic learning, online, higher education. Literature published from 1988 to 2012 was used to gain an 
understanding of the current meaning of collaboration in online learning. Cumulative Index to Nursing and Allied Health Literature yielded 55 results; Education Resources Information Center yielded 102 results; Academic Search Premier yielded 43 articles, Web of Knowledge including Web of Science and Medline yielded 56 articles. In order to identify articles that were potentially relevant to the concept analysis, all titles and abstracts if available were reviewed. This process yielded 107 articles after 149 duplicates were removed. These 107 articles were retrieved and reviewed. The literature that specifically discussed collaboration or collaborative learning using any form of online education was considered relevant. On closer evaluation 48 articles were found to not be relevant as they discussed collaboration among faculty, practitioners, and developers in the development of a course rather than collaboration among students. A final sample of 59 articles and four books were used for analysis. The final sample of articles includes review papers, theoretical studies, research papers, expert opinion and educational innovations that represent a wide variety of academic majors such as computer science, business, nursing, education, and social work.

\section{Data Collection and Analysis}

The data was initially placed in an excel spreadsheet identifying the author, title, journal, and a few notes about the article. This involved the first readings of the articles retrieved to grasp an overall state of the literature. The data was then analyzed using Rodger's method. Each article was read and coded for antecedents, attributes, consequences, definitions, related concepts and surrogate terms. All the information was initially managed in excel. Identified terms and phrases were then sorted with prevalent themes written on index cards and the frequency of occurrence noted.

\section{Findings}




\section{Identification of the Concept and Associated Expressions}

There is agreement in the literature that collaboration between groups of people from a wide range of settings such as business, non profits, health organizations and educational institutions have led to better outcomes than could have been achieved by working alone. However, its definition remains inconsistent and theoretical (Gajda, 2009). Collaboration in nursing practice has been conceptualized as both a dynamic process in which the group moves through different developmental stages and as an outcome in which there is a synthesis or merging of different perspectives in understanding complex problems and coming to a solution (Gardner, 2005). A variety of different terms have been used to define collaboration as either an outcome or a process. Frequently associated expressions include terms such as joint ventures, networks, partnerships, coalitions, alliances, groups, cooperation, and teamwork (Gajda, 2009; Vallance et al., 2009).

As early as 1989, cooperative learning was a term used to describe a new form of instruction in which groups of students could work together online (Dede, 1989). Cooperative learning along with group work, group interaction, group learning and teamwork continue to be commonly used interchangeably with collaboration in educational settings (Nevgi, Virtanen, \& Niemi, 2006; Vallance et al., 2009). Given the far-reaching and extensive use of the term, this concept analysis was narrowed to define virtual collaboration among students within the asynchronous online learning environment to delineate the focus for analysis.

\section{Attributes}

Identifying the attributes of a concept reflects the real definition of a concept making it possible to identify situations that fall under the concept (Rodgers, 2000)., Several different phrases and words were used in discussing collaboration and many of these words reflected 
group and individual characteristic such as trust, respect, support, commitment and interdependence. Rarely was collaboration specifically defined. Instead a collaborative process was assumed to be part of online education with the use of terms such as collaborative learning and learning communities. Palloff and Pratt (2005) refer to collaboration as the "heart and soul" of online education (p. 6). Most of the articles focused on the assessment and outcomes of collaborative learning. However, four attributes were consistently noted. They were sharing, conflict resolution, reflection and co-construction of knowledge.

Sharing. Sharing on many different levels embodied the essence of the collaborative process within online education. Without sharing, collaboration would not be possible. Sharing in a learning community online was identified as early as 1998 at a webnet world conference (Hiltz, 1998). Sharing continues to be an enduring attribute of the collaborative process. It is described in many different ways such as elaboration of thoughts by Benbunan-Fich \& Arbaugh (2006) and frequent and higher level communication with active participation by Caballe, Daradoumis, Xhafa \& Conesa (2010). Sharing is frequently described as needing to be supportive, respectful, inclusive and trusting in which social interaction and group cohesion is evident (Kiteley \& Ormrod, 2009; Tseng, Ku, Wang, \& Sun, 2009). Further, sharing embodied a sense of belonging to a group or online community in which there was equality among the students resulting in an interdependence and democracy in the sharing process (Jahng, Nielsen, \& Chan, 2010; Kiteley \& Ormrod, 2009; Thompson \& Ku, 2010).

Conflict resolution. Collaboration involves students working together and several authors referred to working through conflict as a requirement for the collaborative process to be successful. Misunderstanding is common in online communication due to the difficulty to process social and emotional cues. If students avoid working through conflict that arises from 
these misunderstandings, communication remains at a superficial level (Caballe et al., 2010; Jahng et al., 2010).

Reflection. The nature of virtual collaborative promotes reflection as it provides the student with the unique opportunity to think about other student's postings while creating their own. This results in deeper understanding of the material studied (Kim, Hong, Bonk, \& Lim, 2011).

Co-construction of knowledge. This attribute implies shared meaning or interpretation with multiple points of view being expressing as ideas are developed and synthesized (Guilar \& Loring, 2008; Harasim, 2012). Co-construction of knowledge has been a defining attribute of collaboration in online education for many years and remains one to the present time. Yakimovicz and Murphy (1995) were "astonished at the rapidity with which the class coalesced as a single entity while individual students constructed knowledge through ongoing interaction and discussion (p. 208). Harasim (2012) identified collaboration as key to building knowledge.

\section{Current State of Knowledge}

Although collaboration and cooperation are often used interchangeably, there is a beginning delineation noted between them. Tutty and Klein (2008) differentiated collaboration from cooperation by placing these concepts on either end of a continuum. Learning strategies that were loosely structured were collaborative and those that were highly structured were cooperative. Harasim (2012) identified cooperative learning as division of labor in which individual group members contributed to the whole and collaborative learning as co-labor to produce a result based on discourse.

\section{Antecedents}


Analysis of the literature revealed four antecedents which are those factors that must be present before the existence of a concept (Rodgers, 2000). The four antecedents are classified as constructivism, web based technology, group-based process with a shared purpose and support. There may be some overlap between the antecedents and attributes. For example, group process is required in order for collaboration to occur but it is also an ongoing developing process as students are collaborating. The same holds true for support. Students require support to learn the technology prior to being able to collaborate but also require ongoing support throughout the collaborative process.

Constructivism. The most commonly noted antecedent for collaboration in the online learning environment was a foundation in constructivism. Constructivist learning theory suggests that learning is an active process in which learners make meaning of new information and construct new knowledge within a social milieu rather than passively acquiring it (Guilar \& Loring, 2008; Jahng et al., 2010). Collaborative learning has been influenced by constructivism and constructivist theory has been popularized under the term collaborative learning (Michinov \& Michinov, 2008; Vallance et al., 2009). Computer supported collaborative learning is related to constructivism as online courses place emphasis on learners construction of knowledge through interaction with each other (Zenios, 2011).

Web based technology. A web-based platform that provides a space for students to interact with each other in groups is needed in order for collaboration to occur. Further to the infrastructure, well designed assignments using the technology are needed for students to effectively collaborate (Du, Zhang, Olinzock, \& Adams, 2008; Fung, 2004; Klein \& Solem, 2008; Lee \& Tsai, 2011; Legg, Adelman, Mueller, \& Levitt, 2009). 
Group process with a shared purpose. Collaboration involves working with people in groups that have a shared purpose. There needs to be a social presence in order to build trust and willingness to share rather than hoard knowledge (Jahng et al., 2010; Smith, 2011). Group members need to be committed and take active responsibility for their own work and the outcome of the group's work (Oliveira, Tinoca, \& Pereira, 2011).

Support. Several articles mentioned the need for support in order for students to learn to collaborate. Technical, social, task, and group support when first attempting to communicate online facilitates students learning to collaborate with each other (Caballe et al., 2010; Tseng et al., 2009). Faculty needs to take an active role in supporting students in learning to collaborate online. This support can take many different forms such as initially encouraging peer-to-peer interaction and making positive observations about student participation. A more advanced level of support is demonstrated by encouraging students to make connections between ideas among learners (Boettcher \& Conrad, 2010).. Inherent in providing support is the presence and responsiveness of the faculty member within the online learning environment.

\section{Consequences}

Rodgers (2000) defines consequences as events that occur as a result of the concept. There were two main consequences identified in the literature. They were higher order thinking and learning to work with others. Higher order thinking was discussed in five significant ways (1) problem solving and critical thinking skills (Tseng et al., 2009; Vallance et al., 2009) (2) resolving difficulties and decision making (Karakaya \& Şenyapılı, 2008) (3) deeper understanding and creation of their own knowledge and group solutions to complex problems (Jahng et al., 2010; Michinov \& Michinov, 2008; Tutty \& Klein, 2008) (4) the ability for 
students to make adjustments in their own thinking after listening to others (Du et al., 2008;

Guilar \& Loring, 2008) and (5) learning to self reflect before responding (Kim et al., 2011).

A virtual collaborative process also resulted in students learning to work with others in meaningful ways, drawing on each other's strengths and weaknesses (Ciesielka, 2008). Students were more engaged in the group process. In doing so, they learned about them selves, gained appreciation of others, and had a more positive view of teamwork. They began to appreciate that accomplishment and task quality were a result of group effort rather than individual capabilities (Havard, Du, \& Xu, 2008; Jahng et al., 2010; Karakaya \& Şenyapılı, 2008)

\section{Exemplar}

Two exemplars are identified from the literature in keeping with the inductive nature of Rodgers' concept analysis. The purpose is to provide a practical demonstration of the concept in a relevant context (Rodgers, 2000). The first exemplar provided in the appendix illustrates the concept of virtual collaboration. This asynchronous discussion offered by Palloff and Pratt (2007) is about the possibility of creating a separate discussion forum for students to reflect on process issues while studying management and organizational behavior. The discussion demonstrates the attribute of sharing in that the class engaged in a respectful, democratic sharing of ideas in coming to a decision about the idea of a separate forum presented by the faculty member, Rena.

The attributes of construction of knowledge and reflection were demonstrated when one of the students, Judie, commented that the question of creating a separate forum for reflection was relevant to business. She alluded to a parallel process by identifying the importance of attending to both task and process management. Another student, Keith, followed this up by relating the issue of task and process management to theory learned in the course and made 
connections to learning in another class. Another student, Tania, raised some concerns, which were validated by the faculty member.

The attribute of conflict resolution was not overtly present which is a limitation of this exemplar. However, one of the students mentioned that there was a time in a previous quarter that there were complaints about too many forums, which may reflect a conflict that was worked through by this group of students as they became more comfortable with the technology.

Rodgers (2000) recommends using more than one exemplar to illustrate a practical example if needed. The following exemplar also offered by Paloff and Pratt (2007) more clearly illustrates the attribute of conflict resolution.

I'm having a hard time understanding all the heat around defining community......I realize that the purpose of this seminar is to debate issues around community and to define what the intersection is between the "human" and "virtual" communities. I also realize that we will disagree on what those elements are and that sometimes that disagreement will get heated. That's fine with me. But can we agree to establish a norm that we won't make it personal? I think that if we can, we may move through some of the conflict into some really important ideas about what compromises community. Claudia (p. 38).

In this exemplar the student recognizes that some members of the group are not being respectful of each other when disagreeing. She offers a way to make disagreement safer, which led to the group members feeling a deeper sense of connection to each other and a more positive learning outcome (Palloff and Pratt, 2007).

\section{Theoretical Definition}


The following definition is offered for virtual collaboration in the context of online learning: an interdependent and democratic online group process grounded in constructivist pedagogy in which students debate and reflect on shared knowledge, to construct new understanding of relevant information. This definition encompasses the attributes of sharing, conflict resolution, reflection, and co-construction of knowledge.

\section{Implications for Nursing Education and Further Inquiry}

Online learning in nursing education has been evolving at a rapid pace (Billings \& Halstead, 2009). At the same time, nurse leaders in education have been embarking on curriculum reform to meet the educational needs of nursing students to better prepare them for today's healthcare environment. This curriculum reform involves a shift from content to a concept driven curriculum. With this shift comes a change in teaching strategies in which active learning and critical thinking skills are fostered (Giddens et al., 2008). Faculty in a concept driven curriculum become facilitators of learning in which collaborative learning is emphasized, rather than deliverers of content in which students are passive learners (Billings \& Halstead, 2009; Giddens et al., 2008). Group work and discussion boards are often used in online nursing education and these teaching strategies can provide a structure that encourages collaborative learning. To maximize the impact of the learning experience, it is important for faculty to be able to differentiate between cooperation and collaboration in order for students to develop critical thinking skills and deepen their learning. Both skills are needed. Clarification of virtual collaboration prior to using it as a pedagogic tool in the online learning environment will enhance nursing education with the changes in nursing curriculum being implemented today.

Further refinement of the concept as it relates to online learning would benefit from research that seeks to identify the developmental stages of the collaborative process among 
nursing students. Petri (2010) identified that research needs to be centered primarily in the area of measurement. This is relevant to the context of both online learning and practice. How can the presence of virtual collaboration be measured? How can the presence of collaboration in practice be measured? How can the relationship between the use of virtual collaboration and collaboration in practice be measured? A research study that positively correlates the presence of virtual collaboration to collaboration in practice will greatly facilitate the transition from education to practice.

\section{Conclusion}

An analysis of the literature revealed that there is not a consistent clear differentiation between the concepts of collaboration, cooperation and teamwork. Collaboration in online education has been defined in very loose terms, such as student discussions in online environments, to very narrow terms, such as requiring students to work in synchronous online environments. The purpose of this concept analysis was to clarify the current use of concept of virtual collaboration using Rodgers' concept analysis process. Identification and analysis of the attributes, antecedents and consequences of virtual collaboration facilitated the development of a theoretical definition. Exploring the meaning of virtual collaboration in online academic settings is a beginning step towards research aimed at understanding how students learn to collaborate in the online learning environment and how it translates to nursing practice. Operationalizing the theoretical definition and the development of measurement tools will further promote concept development and the transition of education to practice. 


\section{References}

AACN. (2008). The essentials of baccalaureate education for professional nursing practice.

Retrieved from http://www.aacn.nche.edu/education/bacessn.htm

Benbunan-Fich, R., \& Arbaugh, J. B. (2006). Separating the effects of knowledge construction and group collaboration in learning outcomes of web-based courses. Information \& Management, 43(6), 778-793. doi: 10.1016/j.im.2005.09.001

Billings, D. M., \& Halstead, J. A. (2009). Teaching in nursing: A guide for faculty (3rd ed.). St. Louis, MO: Saunders-Elsevier.

Boettcher, J. V., \& Conrad, R. M. (2010). The online teaching survival guide. San Francisco, CA: Jossey-Bass.

Caballe, S., Daradoumis, T., Xhafa, F., \& Conesa, J. (2010). Enhancing knowledge management in online collaborative learning. [Article]. International Journal of Software Engineering \& Knowledge Engineering, 20(4), 485-497. doi: 10.1142/s0218194010004839

Ciesielka, D. (2008). Using a wiki to meet graduate nursing education competencies in collaboration and community health. Journal of Nursing Education, 47(10), 473-476. doi: 10.3928/01484834-20081001-02

Dede, C. (1989). The evolution of distance learning: Technology-mediated interactive learning. Journal of Research on Computing in Education, 22(3). Retrieved from http://www.iste.org/ 
Du, J., Zhang, K., Olinzock, A., \& Adams, J. (2008). Graduate students' perspectives on the meaningful nature of online discussions. Journal of Interactive Learning Research, 19(1), 21-36. Retrieved from http://www.editlib.org/p/21871

Fung, Y. Y. H. (2004). Collaborative online learning: Interaction patterns and limiting factors. Open Learning, 19(2), 135-149. doi: 10.1080/0268051042000224743

Gajda, R. (2009). Building, sustaining, and evaluating organizational collaboration. THe RMC Health Educator, 9(2), 5. Retrieved from http://www.rmc.org/category/rmc-healtheducator/health-educator-articles/

Gardner, D. (2005). Ten lessons in collaboration. Online Journal of Issues in Nursing, 10( 1 ). Retrieved from http://www.nursingworld.org/MainMenuCategories/ANAMarketplace/ANAPeriodicals/OJIN/Ta bleofContents/Volume102005/No1Jan05/tpc26 116008.html

Giddens, J., Brady, D., Brown, P., Wright, M., Smith, D., \& Harris, J. (2008). A new curriculum for a new era of Nursing Education. Nursing Education Perspectives, 29(4), 200-204.

Guilar, J., \& Loring, A. (2008). Dialogue and community in online learning: Lessons from Royal Roads University. Journal of Distance Education, 22(3), 19-40. Retrieved from http://www.jofde.ca/index.php/jde/article/view/52

Harasim, L. (2012). Learning theory and online technologies. New York: Routledge. 
Havard, B., Du, J., \& Xu, J. (2008). Online collaborative learning and communication media. Journal of Interactive Learning Research, 19(1), 37-50. Retrieved from http://www.editlib.org/p/22804

Henneman, E. A., Lee, J. L., \& Cohen, J. I. (1995). Collaboration: A concept analysis. Journal of Advanced Nursing, 21(1), 103-109. doi: 10.1046/j.1365-2648.1995.21010103.x

Hiltz, S. R. (1998). Collaborative learning in asynchronous learning networks: Building learning communities. Paper presented at the WebNet 98 World Conference of the WWW, Internet, and Intranet Proceedings, Orlando, FL. Retrieved from http://eric.ed.gov

Jahng, N., Nielsen, W. S., \& Chan, E. K. H. (2010). Collaborative learning in an online course: A comparison of communication patterns in small and whole group activities. Journal of distance Education, 24(2), 39-58.

Karakaya, A., \& Şenyapılı, B. (2008). Rehearsal of professional practice: Impacts of web-based collaborative learning on the future encounter of different disciplines. [Article]. International Journal of Technology \& Design Education, 18(1), 101-117. doi: $10.1007 / \mathrm{s} 10798-006-9013-1$

Kim, P., Hong, J.-S., Bonk, C., \& Lim, G. (2011). Effects of group reflection variations in project-based learning integrated in a Web 2.0 learning space. [Article]. Interactive Learning Environments, 19(4), 333-349. doi: 10.1080/10494820903210782 
Kiteley, R. J., \& Ormrod, G. (2009). Towards a team-based, collaborative approach to embedding e-learning within undergraduate nursing programmes. Nurse Education Today, 29(6), 623-629. doi: 10.1016/j.nedt.2009.01.010

Klein, P., \& Solem, M. (2008). Evaluating the impact of international collaboration on geography learning. Journal of Geography in Higher Education, 32(2), 245-267. doi: $10.1080 / 03098260701728500$

Lee, S. W.-Y., \& Tsai, C.-C. (2011). Students' perceptions of collaboration, self-regulated learning, and information seeking in the context of Internet-based learning and traditional learning. Computers in Human Behavior, 27(2), 905-914. doi: 10.1016/j.chb.2010.11.016

Legg, T. J., Adelman, D., Mueller, D., \& Levitt, C. (2009). Constructivist strategies in online distance education in nursing. Journal of Nursing Education, 48(2), 64-69. doi: 10.3928/01484834-20090201-08

Michinov, N., \& Michinov, E. (2008). Face-to-face contact at the midpoint of an online collaboration: Its impact on the patterns of participation, interaction, affect, and behavior over time. Computers \& Education, 50(4), 1540-1557. doi:

10.1016/j.compedu.2007.03.002

Nevgi, A., Virtanen, P., \& Niemi, H. (2006). Supporting students to develop collaborative learning skills in technology-based environments. British Journal of Educational Technology, 37(6), 937-947. doi: 10.1111/j.1467-8535.2006.00671.x 
Oliveira, I., Tinoca, L., \& Pereira, A. (2011). Online group work patterns: How to promote a successful collaboration. Computers \& Education, 57(1), 1348-1357. doi: 10.1016/j.compedu.2011.01.017

Palloff, R. N., \& Pratt, K. (2005). Collaborating online: Learning together in community. San Francisco, CA: Jossey-Bass.

Palloff, R. N., \& Pratt, K. (2007). Building online learning communities: Effective strategies for the virtual classroom (2nd ed.). San Franscico, CA: John Wiley \& Sons.

Petri, L. (2010). Concept analysis of interdisciplinary collaboration. Nursing Forum, 45(2), 7382. doi: 10.1111/j.1744-6198.2010.00167.x

Rodgers, B. L. (2000). Concept analysis: An evolutionary view. In B. L. Rodgers \& K. A. Knafl (Eds.), Concept development in nursing: Foundations, techniques, and applications (2nd ed., pp. 77-102). Philadelphia: Saunders.

Smith, R. O. (2011). Trust in Online Collaborative Groups: A Constructivist Psychodynamic View. Adult Learning, 22(2), 19-23.

Thompson, L., \& Ku, H.-Y. (2010). Degree of online collaboration and team performance: A case study. Quarterly Review of Distance Education, 11(2), 127-134. Retrieved from http://www.infoagepub.com/quarterly-review-of-distance-education.html 
Tofthagen, R., \& Fagerstrøm, L. M. (2010). Rodgers' evolutionary concept analysis - a valid method for developing knowledge in nursing science. Scandinavian Journal of Caring Sciences, 24, 21-31. doi: 10.1111/j.1471-6712.2010.00845.x

Tseng, H., Ku, H.-Y., Wang, C.-H., \& Sun, L. (2009). Key factors in online collaboration and their relationship to teamwork satisfaction. Quarterly Review of Distance Education, 10(2), 195-206. Retrieved from http://www.infoagepub.com/quarterly-review-of-distanceeducation.html

Tutty, J., \& Klein, J. (2008). Computer-mediated instruction: A comparison of online and faceto-face collaboration. [Article]. Educational Technology Research \& Development, 56(2), 101-124. doi: 10.1007/s11423-007-9050-9

Vallance, M., Towndrow, P., \& Wiz, C. (2009). Conditions for successful online document collaboration. TechTrends: Linking Research \& Practice to Improve Learning, 54(1), 2023. doi: 10.1007/s11528-009-0359-6

Yakimovicz, A. D., \& Murphy, K. L. (1995). Constructivism and collaboration on the internet: Case study of a graduate class experience. Computers \& Education, 24(3), 203-209. doi: 10.1016/0360-1315(95)00015-E

Zenios, M. (2011). Epistemic Activities and Collaborative Learning: Towards an Analytical Model for Studying Knowledge Construction in Networked Learning Settings. Journal of Computer Assisted Learning, 27(3), 259-268. 